Int. J. Speleol. 11 (1981), pp. 49-62.

\title{
Some Implications of Competition for Cave Stream Communities
}

\author{
David C. Culver*
}

\begin{abstract}
SUMMARY
Based on recent theoretical work by Robert May and Richard Levins, two hypotheses about time fluctuations in abundance of competing species were generated. Data for isopods and amphipods from four cave stream communities in Virginia and West Virginia were used to test the predictions. First, variance of total abundance should be less than the sum of the variances of individual species' abundances. In three of four communities studied, the prediction was confirmed, but none were statistically significant. Positive correlations among carrying capacities of competing species may explain the poor agreement with predictions. Second, the signs of 19 correlations and partial correlations of species abundances were predicted on the basis of relative magnitudes of direct and indirect effects of competition, and of these predictions, 16 were confirmed by the data, including 5 statistically significant ones. Most interesting was the finding that competitors can be positively correlated.
\end{abstract}

As Poulson and White (1969) point out, caves can be important "laboratories" for testing and elaborating on ecological models and theories. The purpose of this paper is to explore some of the consequences of intraspecific and interspecific competition for the structure and dynamics of some aquatic cave communities.

The data to be analyzed are from cave streams in the south central Appalachians. These cave streams contain between two and four competing amphipod and isopod species. Considerable evidence has been marshalled in previous publications (Culver, 1970, 1971, 1973, 1976) that the amphipods and isopods in these streams compete primarily for space, and this evidence will not be reviewed here. Rather, competition is assumed to be occurring in the communities being studied, and the consequences of competition for temporal changes in species abundance will be pursued.

These communities are especially appropriate for the study of competition models because the dynamics of the interaction $\left(f_{j}\right)$ are fairly well described by the standard competition equations:

$$
\mathrm{f}_{\mathrm{i}} \approx \frac{\mathrm{dN} \mathrm{N}_{\mathrm{i}}}{\mathrm{dt}}=\frac{\mathrm{r}_{\mathrm{i}} \mathrm{N}_{\mathrm{i}}}{\mathrm{K}_{\mathrm{i}}}\left(\mathrm{K}_{\mathrm{i}}-\sum_{\mathrm{j}=1}^{\mathrm{n}} \alpha_{\mathrm{ij}} \mathrm{N}_{\mathrm{j}}\right)
$$

* Department of Biological Sciences Northwestern University, Evanston, Illinois 60201 U.S.A. . 
where $\mathrm{N}_{\mathrm{i}}$ is the population size of species $\mathrm{i}, \mathrm{r}_{\mathrm{i}}$ is its intrinsic rate of increase, $\mathrm{K}_{\mathrm{i}}$ is the carrying capacity of the environment for species $\mathrm{i}$, and $\alpha_{\mathrm{ij}}$ is the effect of an individual of species $\mathrm{j}$ on an individual of species $\mathrm{i}\left(\alpha_{\mathrm{ii}}=1\right)$. Some of the assumptions contained in equation [1], such as the constancy of the carrying capacity and the absence of higher order terms, make equation [1] inappropriate for some communities (e.g., Neill, 1974). However, they seem to work quite well in cave stream communities for several reasons (Culver, 1973, 1976). First, populations appear to be near equilibrium and aside from periods of spring flooding, population sizes vary less than populations in epigean streams (Culver, 1971). Other researchers (e.g., Gledhill, 1977) have remarked on the relative constancy of subterranean aquatic faunas. Second, the communities are simple, with between two and four interacting species. This reduces the mathemaical chances of cyclic or chaotic behavior of population sizes (Smale, 1976). Third, the interactions between species are behaviorally simple and highly stereotyped (Culver, 1970), and thus they are unlikely to result in complicated, higher order interaction terms resulting from density or age differences. These conditions taken together indicate that communities should be at or near the equilibrium:

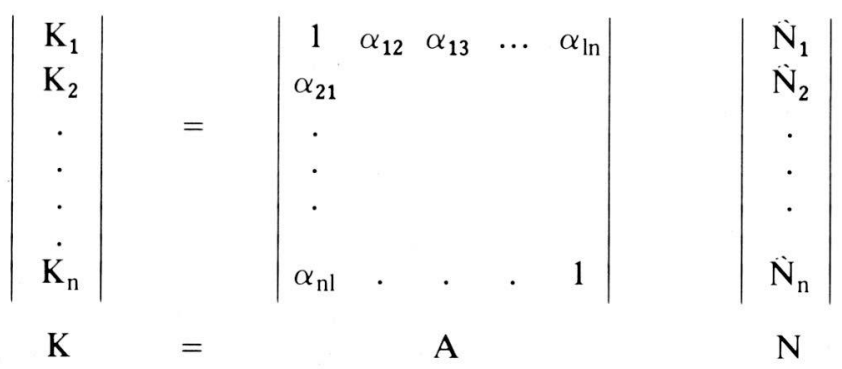

where $\hat{N}_{i}$ is the equilibrium population size of species $i$.

The pioneering theoretical work by May (1974a) and Levins (1975) has resulted in a series of predictions being made about communities of competitors near equilibrium. In this paper, two of these predictions will be examined:

(1) the variation in total abundance of all species combined over time should be less than variation over time of population size of individual species.

(2) the partial correlation of abundances of competing species over time should be negative but correlations can be positive if indirect competition is important.

Although the genesis of these predictions comes from mathematical ecology, a verbal description of each prediction will be given first for the aid of readers who are not mathematically inclined. A synopsis of the mathematical argument will follow.

Time series data for four caves in Virginia and West Virginia form the 
data base for this study. Species compositions for these four caves are given in Table 1.

Table 1. Species compositions for the four communities studied. Data on individual species abundances through time are given in Appendix 1. Data for Spangler and Gallohan Cave No. 2 are from Dickson (1976); data for Gallohan Cave No. 1 are from unpublished work of James Estes; data for Court Street Cave are the author's.

\begin{tabular}{lcccc}
\hline SPECIES & $\begin{array}{c}\text { Court } \\
\text { Street }\end{array}$ & $\begin{array}{c}\text { Gallohan } \\
\text { No. 1 }\end{array}$ & $\begin{array}{l}\text { Gallohan } \\
\text { No. 2 }\end{array}$ & Spangler \\
\hline $\begin{array}{l}\text { AMPHIPODA } \\
\begin{array}{l}\text { Crangonyx antennatus } \\
\text { Stygobromus emarginatus }\end{array}\end{array}$ & $\mathrm{X}$ & $\mathrm{X}$ & $\mathrm{X}$ & $\mathrm{X}$ \\
$\begin{array}{l}\text { Stygobromus spinatus } \\
\text { ISOPODA }\end{array}$ & $\mathrm{X}$ & & & \\
$\begin{array}{l}\text { Caecidotea recurvata } \\
\text { Lirceus usdagalun } \\
\text { Pseudobaicalasellus holsingeri* }\end{array}$ & & $\mathrm{X}$ & $\mathrm{X}$ & $\mathrm{X}$ \\
\hline
\end{tabular}

* The genus Pseudobaicalasellus proposed by Herny and Magniez has not been critically examined by North American Taxonomists (see Bowman, 1975).

\section{PATTERNS OF TOTAL ABUNDANCE}

Imagine a cave stream where the availability of food or some other limiting factor remains roughly constant. That is, the total number of individuals (or total biomass) that the habitat can support remains constant, assuming ecological efficiencies of competing species do not vary greatly. So long as there has been sufficient time for a population or populations to reproduce to reach this maximum, the intensity of interspecific competition has little effect on the total number of individuals (or biomass) in the community. On the other hand, variation in abundance or biomass of individual species would increase with increasing interspecific competition. Therefore, we would predict that total abundance should vary less than the abundance of individual species.

The hypothesis can be framed in a more rigorous way as follows. For the equilibrium in equation [2] to be stable, the eigenvalues of A must have positive real parts (Strobeck, 1973). [For a discussion of eigenvalues see Searle (1966)] The real parts of the eigenvalues measure the rate of return of the community to the equilibrium following a perturbation. Associated with each eigenvalue is an eigenvector, which is a linear combination of the variable of the differential equation underlying the process. In this case, the variables are population sizes, or deviations of population sizes from the equilibrium point. The rate of return following a particular perturbation depends on 
which eigenvector(s) most closely approximates the perturbation. For example, if in a three species community the abundances of the first two species are increased and the abundance of a third is decreased, then the rate of return to equilibrium will be governed by eigenvalues associated with eigenvectors whose first two elements are positive and last one is negative. An important consequence of the assumption that all species are competing (i.e., $\alpha_{\mathrm{ij}}>0$ ) is that the eigenvector associated with the largest eigenvalue has all positive coefficients and all other eigenvectors have at least one negative coefficient- -the Perron-Frobenius Theorem (Gantmacher, 1959). Therefore, a perturbation that changes the abundance of all species will disappear more quickly than other perturbations. For many matrices with biologically reasonable values for $\alpha_{\mathrm{ij}}$, all of the coefficients of the eigenvector are one (May, 1974b), and the sum of the elements of the eigenvector corresponds exactly to total abundance. Any perturbation of the community aside from one involving total abundance will have a slower rate of return to equilibrium since it will be controlled by smaller eigenvalues. Figure 1 is a graphical representation of this hypothesis for two competitors.

The hypothesis to be tested is that for time-series data, the variance of total abundance $\left(\mathrm{V}_{\mathrm{T}}\right)$, which is controlled by the largest eigenvalue, is less than the sum of the individual species' variance $\left(\mathrm{V}_{\mathrm{i}}\right)$, which are controlled by the other, smaller eigenvalues. This can be statistically tested by using an F-test:

$$
\frac{\sum_{\mathrm{i}=1}^{\mathrm{n}} \mathrm{V}_{\mathrm{i}}}{\mathrm{V}_{\mathrm{T}}}=\mathrm{F}[(\mathrm{m}-1)(\mathrm{n}),(\mathrm{m}-1)]
$$

for $\mathrm{n}$ species and $\mathrm{m}$ sampling dates. Since

$$
\mathrm{V}_{\mathrm{T}}=\sum_{\mathrm{i}=\mathrm{l}} \mathrm{V}_{\mathrm{i}}+\sum_{\substack{\mathrm{i}, \mathrm{j}=\mathrm{l} \\ \mathrm{j}>\mathrm{i}}}^{\mathrm{n}} 2 \operatorname{cov}\left(\mathrm{N}_{\mathrm{i}}, \mathrm{N}_{\mathrm{j}}\right)
$$

where $\mathrm{N}_{\mathrm{i}}$ is the abundance of species $\mathrm{i}$, then it follows that the sum of the covariances of species abundances for competing species is negative, as can be seen in figure $1 \mathrm{~B}$.

In three of the four caves, the variance of total abundance is less than the sum of the variances of abundances of individual species (Table 2). The variance ratios range from 2.39 in Gallohan Cave No.2 to 0.98 in Gallohan Cave No. 1. None are statistically significant. If variance ratios in Table 2 are typical for communities of competitors, sufficient data will rarely be available to demonstrate statistical significance.

All in all, the fit of the data to the prediction is poor. This may be due in part to small sample sizes, but it also seems likely that some other process is involved. The hypothesis above was generated for the situation where the 

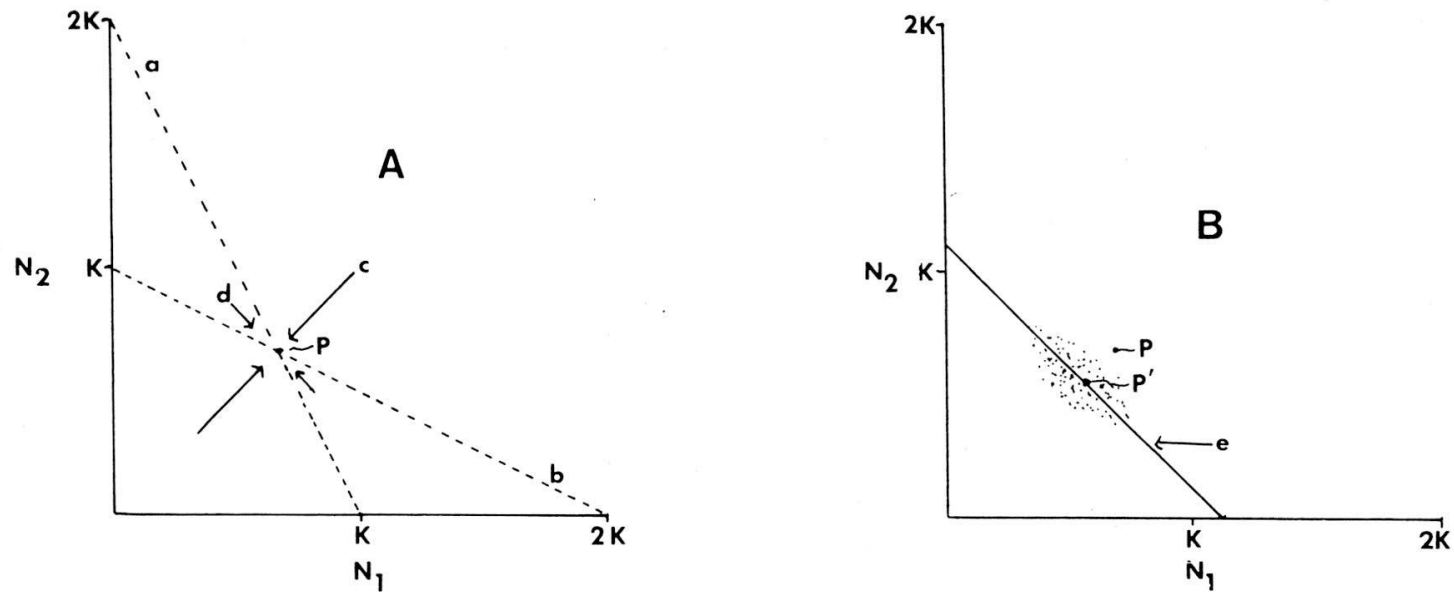

Fig. 1. An illustration of the hypothesis derived from the Perron-Frobenius Theorem for two competing species. The growth rate of each species is assumed to be $\mathrm{dN} / \mathrm{dt}=(\mathrm{rN} / \mathrm{K})\left(\mathrm{K}-\mathrm{N}-\alpha \mathrm{N}_{2}\right)$. In $\mathrm{A}$, the dashed lines are isoclines for the two species when $\alpha=0.5$. Line $\mathrm{a}$ is the isocline for species 1 anc line $b$ is the isocline for species 2 . The stable equilibrium point is $p$. The solid arrows are the two eigenvectors. The length of the arrow indicates the relative magnitude of the eigenvalue associated with the eigenvector. Assuming that $(\mathrm{r} N / \mathrm{K})=1$, eigenvector $\mathrm{c}$ is $(1,1)$ and $\lambda_{c}=1+\alpha$. This is the eigenvector of total abundance. The eigenvector $\mathrm{d}$ is $(1,-1)$ and $\lambda_{d}=1-\alpha$. This eigenvector is the difference in abundance of the two species. In B, the equilibrium distribution through time in a varying environment is indicated by the cloud of dots. The mean population sizes ( $\left.p^{\prime}\right)$ will be less than in the deterministic case (see May, 1973). Line e is a line for which $N_{1}+N_{2}=$ constant. The largest eigenvalue will tend to return populations to this line. Fluctuations along line e will be less strongly damped. 
Table 2. The ratio of the sum of the variances of individual species abundances $\left(\xi V_{j}\right)$ to the variance of total abundance $\left(\mathrm{V}_{\mathrm{T}}\right)$. If species are competing, this ratio should be greater than unity. The number of samples required for statistical significance $(\mathrm{P}>0.95)$ if the ratio observed is the true variance ratio, is listed in the column labelled $\mathrm{N}^{*}$.

\begin{tabular}{lcccc}
\hline Cave & No. of Species & No. of time samples & $\xi \mathrm{V}_{\mathrm{i}} / \mathrm{V}_{\mathrm{T}}$ & $\mathrm{N}^{*}$ \\
\hline Gallohan No. 1 & 3 & 4 & 2.39 & 12 \\
Court Street & 3 & 7 & 1.77 & 25 \\
Spangler & 2 & 4 & 1.12 & $>100$ \\
Gallohan No. 1 & 3 & 5 & 0.98 & $>100$ \\
\hline
\end{tabular}

equilibrium is fixed and the population sizes are subject to random perturbation about this equilibrium. But the equilibrium itself may vary, especially due to variation in the carrying capacity, K. May (1974a) has shown that if variation in $\mathrm{K}_{\mathrm{i}}$ is random (i.e., 'white noise'), the variance in total abundance should be less than the sum of the variances of individual species' abundances. This results in the same qualitative prediction about variances as does the consequences of the Perron-Frobenius Theorem discussed above. But if carrying capacities of competing species are positively correlated through time, then the variance in total abundance may exceed the sum of the variances of individual species' abundances. For example, if the carrying capacities of two competitors are both low in winter and high in summer, then species abundances might be positively correlated (see equation 3 ) even though they are competing. The mathematics of such cases of competitors with correlated carrying capacities has not been completely worked out (see Roughgarden, 1975), but the importance of correlation of K's can be seen for the following simple case. Let $\mathrm{r}_{\mathrm{i}} \hat{\mathrm{N}}_{\mathrm{i}} / \mathrm{K}_{\mathrm{i}}=1$ for all species and let all interspecific competition coefficients $\left(\alpha_{\mathrm{ij}}\right)$ be equal to a. It can be shown (Levins and Culver, unpublished) that the covariances of changes in abundance of species $i$ and $j$ is:

$$
\operatorname{cov}\left(\triangle N_{i}, \triangle N_{j}\right)=\frac{6_{k}^{2}\left[1+(n-1) a^{2}\right] p-(n-2) a^{2}}{(1-a)[1+(n-1) a]^{2}(n-1)}
$$

Where $\mathrm{p}$ is the product-moment correlation of $\mathrm{K}_{\mathrm{i}}$ and $\mathrm{K}_{\mathrm{j}}$, and $6_{\mathrm{K}}^{2}$ is the variance of $\mathrm{K}$, assuming each $\mathrm{K}_{\mathrm{i}}$ has the same variance. When the covariance in [4] is positive, all covariance will be positive due to symmetry, and the variance of total abundance $\left(\mathrm{V}_{\mathrm{T}}\right)$ will exceed the sum of variances $\left(\mathrm{V}_{\mathrm{i}}\right)$ of individual species abundances (see equation 3 ). This will occur when the correlation of carrying capacities exceed a certain value:

$$
p>\frac{(n-2) a^{2}}{1+(n-1) a^{2}}
$$

For example, for Gallohan Cave No. 1, the mean value of $\alpha$ is 0.9 , and the 
covariance will be positive if the correlation between $\mathrm{K}$ 's is 0.31 or greater, not an especially strong correlation. This line of reasoning cannot be pursued further because the correlation of K's is probably an unmeasureable quantity. Abundances of species themselves cannot be used since they are a result of both carrying capacity and interspecific competition. An independent estimate of $\mathrm{K}$ is needed, and that is not available.

\section{CORRELATIONS AND PARTIAL CORRELATIONS OF ABUNDANCE}

Another consequence of interspecific competition are correlations among species' abundance through time. When two species are competing, the abundances of the two species should be negatively correlated since an increase in one species should result in a decrease in the other. When three species are competing, the situation is more complicated. This is because species A affects species B in two ways. First, there is the direct negative effect of species A on species B. Second, there is the indirect positive effect of species A on species B via species C. That is, species A has a negative effect on species $C$, which has a negative effect on species B; so the overall indirect effect of species $\mathrm{A}$ on species $\mathrm{B}$ is positive. The correlation between the two species depends on the relative magnitude of these effects (Levine, 1976).

In order to make predictions about the sign of the correlation, we must look at the mathematics of the hypothesis a bit more carefully. For convenience and consistency, Levins' (1975) terminology and symbols will be used as much as possible. A change in the growth equations, $f_{i}$ (see equation 1), can be generally written as $\frac{\delta \mathrm{f}_{\mathrm{i}}}{\delta \mathrm{C}_{\mathrm{h}}}$ where $\mathrm{C}_{\mathrm{h}}$ is some parameter that affects the growth rate. This partial derivative can be thought of as a change in growth rate of species due to a change in carrying capacity of species. Changes in growth rate will in turn affect population size of species $i\left(\frac{\delta \mathrm{N}_{i}}{\delta \mathrm{C}_{\mathrm{h}}}\right)$ in the fol lowing way if the population is near equilibrium (Levins, 1975):

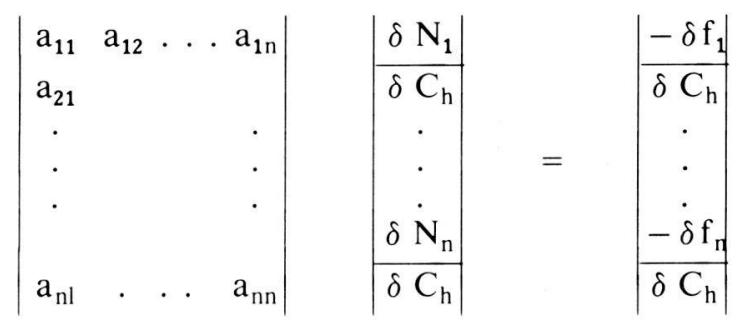

where $a_{i j}$ is the effect of species $\mathrm{j}$ on species $\mathrm{i}$. For the standard competition equations [1], 


$$
\mathrm{a}_{\mathrm{ij}}=\frac{-\mathrm{r}_{\mathrm{i}} \hat{\mathrm{N}}_{\mathrm{i}}}{\mathrm{K}_{\mathrm{i}}} \alpha_{\mathrm{ij}}
$$

The unknowns, i.e., the effect of perturbations $\left(\delta \mathrm{f}_{\mathrm{i}} / \delta \mathrm{C}_{\mathrm{h}}\right)$ on the population sizes, can be found by inverting the matrix in equation [7]. For three competitors:

$\left|\begin{array}{l}\frac{\delta \mathrm{N}_{1}}{\delta \mathrm{C}_{\mathrm{h}}} \\ \frac{\delta \mathrm{N}_{2}}{\delta \mathrm{C}_{\mathrm{h}}} \\ \frac{\delta \mathrm{N}_{3}}{\delta \mathrm{C}_{\mathrm{h}}}\end{array}\right|=\frac{1}{|\mathrm{~A}|}\left|\begin{array}{lll}\left(\mathrm{a}_{22} \mathrm{a}_{33}-\mathrm{a}_{23} \mathrm{a}_{32}\right) & \left(-\mathrm{a}_{33} \mathrm{a}_{12}+\mathrm{a}_{32} \mathrm{a}_{13}\right) & \left(-\mathrm{a}_{22} \mathrm{a}_{13}+\mathrm{a}_{12} \mathrm{a}_{23}\right) \\ \left(-\mathrm{a}_{21} \mathrm{a}_{33}+\mathrm{a}_{23} \mathrm{a}_{31}\right) & \left(\mathrm{a}_{11} \mathrm{a}_{33}-\mathrm{a}_{13} \mathrm{a}_{31}\right) & \left(-\mathrm{a}_{11} \mathrm{a}_{23}+\mathrm{a}_{13} \mathrm{a}_{21}\right) \\ \left(-\mathrm{a}_{22} \mathrm{a}_{31}+\mathrm{a}_{21} \mathrm{a}_{32}\right) & \left(-\mathrm{a}_{11} \mathrm{a}_{32}+\mathrm{a}_{12} \mathrm{a}_{31}\right)\left(\mathrm{a}_{11} \mathrm{a}_{22}-\mathrm{a}_{12} \mathrm{a}_{21}\right)\end{array}\right|\left|\begin{array}{l}-\delta \mathrm{f}_{1} \\ \frac{\delta \mathrm{C}_{\mathrm{h}}}{-\delta \mathrm{f}_{2}} \\ \frac{\delta \mathrm{C}_{\mathrm{h}}}{-\delta \mathrm{f}_{3}} \\ \frac{\delta \mathrm{C}_{\mathrm{h}}}{\mid}\end{array}\right|$

where $|\mathbf{A}|$ is the determinant of the matrix of inter action coefficients $a_{i j}$. Each off-diagonal term $\left(a^{\prime}{ }_{i j}\right)$ is the difference between the direct and indirect effect for species $j$ on species $i$ (see Levine, 1976). Each diagonal term $\left(a^{\prime}{ }_{i i}\right)$ is the determinant of the subcommunity formed by deleting species i. Each element $a^{\prime}{ }_{i j}$ measures the effect of a change in carrying capacity of species $j$ on the population size of species i.

Correlations can be predicted in the following way. A change in $\mathrm{K}_{\mathrm{i}}$ (or any parameter affecting species i directly) results in changes in population sizes of all species- -these are given in column i. The expected correlation between two species due to changes in $\mathrm{K}_{\mathrm{i}}$ in the community can be found by comparing signs of the two appropriate terms in column $\mathrm{i}$.

A concrete example should clarify this. In Gallohan Cave No. 1 and Gallohan Cave No. 2 three species compete, and their competition coefficients are:

\begin{tabular}{l|lll|} 
Crangonyx antennatus & 1 & 1.0 & 1.3 \\
Caecidotea recurvata & 0.3 & 1 & 1.3 \\
Lirceus usdagalun & 1.2 & 0.5 & 1
\end{tabular} \mid

Since $r_{i}, N_{i}$, and $K_{i}$ are all positive numbers, the sign of $a_{i j}$ depends only on the competition coefficients $\alpha_{\mathrm{ij}}$. Following the recipe in equation [9], the elements $\mathrm{a}_{\mathrm{ij}}$ have the following signs:

Change in $\mathrm{K}$ of:

C.a. C.r. L.u.

\begin{tabular}{ll|lll} 
Effect on & C.a. & + & - & 0 \\
Population Size & C.r. & + & - & - \\
of: & L.u. & - & + & +
\end{tabular}


If only the carrying capacity of one species, say Lirceus usdagalun, is varied $\left(\frac{\delta \mathrm{f}_{3}}{\delta \mathrm{C}_{\mathrm{h}}} \neq 0\right)$, then expected correlations would depend only on column 3 ,

since $\delta \mathrm{f}_{1} / \delta \mathrm{C}_{\mathrm{h}}$ and $\delta \mathrm{f}_{2} / \delta \mathrm{C}_{\mathrm{h}}$ are zero. However the carrying capacities of all species are likely to vary, and so correlation between species $\mathrm{i}$ and species $\mathrm{j}$ depends on all elements in row $\mathrm{i}$ and $\mathrm{j}$. In particular, we expect a positive correlation between two species $i$ and $j$ when the product of the elements $a_{i k} \times a_{j k}$ is zero or has the same sign for each value of $k$, i.e., for the entire row. Thus $C$. antennatus and $C$. recurvata should be positively correlated. If $\mathrm{a}_{\mathrm{ik}}$ and $\mathrm{a}_{\mathrm{jk}}$ have the same sign for the entire row (i.e., for all k) then there should be a negative correlation. Thus L. usdagalun should be negatively correlated with both $C$. antennatus and $C$. recurvata. If for some k's $\mathrm{a}_{\mathrm{ik}}$ times $\mathrm{a}_{\mathrm{jk}}$ is positive and negative for others, no prediction is possible unless the relative magnitude of the initial fluctuations is known.

The predictions about correlations depend critically on the signs of all elements $a_{i j}$. Therefore, Levine's (1976) procedure of dividing $a^{\prime}{ }_{i j}$ by $a^{\prime}{ }_{i i}$ to normalize the matrix may produce confusion. Since, ${ }^{\prime}{ }_{i i}$ can be negative (see $a_{22}$ above), row signs will be changed which would result in the wrong prediction about correlation. Note that if $a^{\prime}{ }_{i i}$ is negative, the sub-community formed by deleting species $i$ is unstable. Such unstable sub-communities may be common for competitors showing interference competition.

Similar predictions can be made for the three species in Court Street Cave, although accurate quantitative measurements are not available. The derivation of the predictions is given in Appendix 2 and summarized in the following table of signs for equation [9]:

\section{Pseudobaicalasellus holsingeri}

Stygobromus emarginatus

\section{Stygobromus spinatus}

$$
\left|\begin{array}{lll}
+ & - & - \\
- & + & + \\
- & + & +
\end{array}\right|
$$

Thus $S$. emarginatus and $S$. spinatus should be positively correlated and both should be negatively correlated with $P$. holsingeri.

In contrast with correlation coefficients, all partial correlations of competitors should be negative. This is because of the close correspondence between the definition of partial correlation and the definition of the competition coefficients (see Seifert and Seifert, 1976). Both essentially measure the effect (or correlation) of species $j$ on species $i$ with all other variables (i.e., population sizes of the other species) held constant.

Using Dickson's data for Spangler Cave and Gallohan Cave No. 2 (Dickson, 1976), Estes' unpublished data on Gallohan Cave No. 1, and my data on Court Street Cave, observed correlations and partial correlations can be compared with predictions (Table 3).

Of the 19 predictions about the signs of correlations and partial correlations, 16 are in agreement with the signs of the calculated values. This level of 
agreement would be attained on a chance basis with a probability of only 0.002 (Sign Test). In addition, five of these correlations were statistically significant (Table 3). Especially interesting is the complete agreement of observed and predicted correlations and partial correlations for Gallohan Cave No. 2. The time period of sampling in Gallohan No. 2 covers the period of the invasion of L. usdagalun (Dickson, 1976), a time of intense competition, but when the population are far from equilibrium. This suggests that the linear models used may hold far from equilibrium.

The interaction between Crangonyx antennatus and Caecidotea recurva-

Table 3. Comparison of observed and predicted correlations and partial correlations of species abundance through time.

\begin{tabular}{|c|c|c|c|c|c|c|}
\hline \multirow[b]{2}{*}{ CAVE SPECIES PAIR } & \multicolumn{3}{|c|}{ PARTIAL CORRELATION } & \multicolumn{3}{|c|}{ CORRELATION } \\
\hline & Predicted & Observed & $\mathbf{P}$ & Predicted & Observed & $\mathbf{P}$ \\
\hline $\begin{array}{l}\text { Spangler: } \\
\text { C. recurvata } \\
\text { C. antennatus }\end{array}$ & - & $-0.34^{*}$ & N.S. & - & $-0.34^{*}$ & N.S. \\
\hline $\begin{array}{l}\text { Gallohan No. 2: } \\
\text { C. recurvata } \\
\text { C. antennatus }\end{array}$ & - & -0.99 & $>0.99$ & + & +0.28 & N.S. \\
\hline $\begin{array}{l}\text { Gallohan No. 2: } \\
\text { C. antennatus } \\
\text { L. usdagalun }\end{array}$ & - & -0.99 & $>0.99$ & - & -0.57 & N.S. \\
\hline $\begin{array}{l}\text { Gallohan No. } 2: \\
\text { C. recurvata } \\
\text { L. usdagalun }\end{array}$ & - & -0.99 & $>0.99$ & - & -0.95 & $>0.95$ \\
\hline $\begin{array}{l}\text { Gallohan No. 1: } \\
\text { C. recurvata } \\
\text { C. antennatus }\end{array}$ & - & +0.30 & N.S. & + & +0.11 & N.S. \\
\hline $\begin{array}{l}\text { Gallohan No. 1: } \\
\text { C. antennatus } \\
\text { L. usdagalun }\end{array}$ & - & -0.82 & N.S. & - & -0.82 & $>0.95$ \\
\hline $\begin{array}{l}\text { Gallohan No. 1: } \\
\text { C. recurvata } \\
\text { L. usdagalun }\end{array}$ & - & +0.05 & N.S. & - & +0.07 & N.S. \\
\hline $\begin{array}{l}\text { Court Street: } \\
P . \text { holsingeri } \\
\text { S. emarginatus }\end{array}$ & - & -0.36 & N.S. & - & -0.38 & N.S. \\
\hline $\begin{array}{l}\text { Court Street: } \\
P . \text { holsingeri } \\
\text { S. spinatus }\end{array}$ & - & -0.51 & N.S. & - & -0.48 & N.S. \\
\hline $\begin{array}{l}\text { Court Street: } \\
\text { S. emarginatus } \\
\text { S. spinatus }\end{array}$ & - & -0.01 & N.S. & + & +0.19 & N.S. \\
\hline
\end{tabular}

* Correlation and partial correlation are identical because there are only two species in the community. 
ta epitomizes the importance of indirect effects in the organization of communities. When no other competitors are present (Spangler Cave), the two species are negatively correlated. When a third competitor is present (Gallohan Cave No. 1 and Gallohan Cave No. 2), the two species are positively correlated.

\section{DISCUSSION}

The ratio of the sum of individual species' variances to the variance of total abundance of the species is a convenient way to summarize competitive effects in a community. However, available data (Table 2) indicate that this ratio may be unlikely to be large enought to be statistically significant unless very large numbers of samples are taken. Furthermore, possible correlations among carrying capacities ( $\mathrm{K}_{\mathrm{i}}$ 's) of the different species can result in the above variance ratios being less than one, even though the species are competing. This has apparently happened in the community in Gallohan Cave No. 1. So, for real communities this ratio is unlikely to be of great value.

The results of the correlation and partial correlation analysis are much more convincing. The high level of agreement between the observed and expected correlations and partial correlations (Table 3) provides strong support for the hypothesis that linearized models of competition are sufficient to describe temporal fluctuations in species' abundance. It is also clear that competitors can be positively correlated- -not only in theory but in actuality (Table 3).

The potential for positive correlations among competitors has important implications for perturbation experiments. It is claimed (e.g., Connell 1975) that perturbation experiments are the only clear way to demonstrate interspecific competition. But the possibility of positive correlation among competitors means that increasing one species may actually increase another competing species, leading one to conclude that the competitor was actually a mutualist or the prey of the other species. Thus perturbation experiments are as difficult to interpret as the indisturbed temporal patterns.

It should be remembered that the hypotheses discussed in this paper are based on linear models. There has been a feeling among many ecologists that the usual models of competition (equation 1) do not contain sufficient complexity to explain interactions in the real world (e.g. Ayala et al., 1973). However, much of the apparent simplicity of standard competition models is due to considering only two competing species. The addition of just one additional species allows for qualitatively new results, such as positive correlations among competitors. Still other possible patterns of fluctuation of three competing species are not possible when two species are present (May and Leonard, 1975). Communities with small numbers of interacting species, such as cave stream communities and desert ant communities (Davidson, 1980), should play an important role in testing species interaction theory. 


\section{ACKNOWLEDGMENTS}

Discussions with Richard Levins and Diane Davidson provided a great many clarifications and ideas. Gary Dickson and James Estes generously provided data from Virginia caves. John Holsinger assisted with field work.

\section{RÉSUMÉ}

Sur la base d'un travail théorique de Robert May et Richard Levins, deux hypothèses sur les fluctuations dans le temps de l'abondance d'espèces en compétition ont été émises. Les données relatives aux espèces d'Isopodes et d'Amphipodes appartenant aux communautés biologiques de quatre cours d'eau souterrains de Virginie et Virginie Occidentale ont été utilisées pour tester ces hypothèses.

Premièrement: la variance de l'abondance totale devrait être inférieure à la somme des variances de l'abondance de chaque espèce prise isolément. Dans trois des quatre communautés étudiées, l'hypothèse s'est vérifiée, mais en aucun cas d'une manière statistiquement significative. L'existence de corrélations positives entre les capacités biotiques propres à chacune des espèces en compétition pourrait expliquer la médiocre coïncidence entre prédictions et observations.

Deuxièment, le signe de 19 corrélations ou corrélations partielles concernant l'abondance des espèces a été prévu théoriquement, en fonction de l'amplitude relative des effets directs ou indirects de la compétition. Parmi ces prévisions, 16 ont été confirmées par les observations, dont 5 d'une manière statistiquement significative. La découverte la plus intéressante réside dans le fait que des corrélations positives peuvent exister entre des espèces compétitrices.

\section{LITERATURE}

AYALA, F.J., M.E., GILPIN, and J.G. EHRENFELD 1973. Competition between species: theoretical models and experimental tests. Theoret. Popul. Biol. 4: 331-356.

BOWMAN, T.E. 1975. Three new troglobitic asellids from western North America (Crustacea: Isopoda: Asellidae). Int.J.Speleol. 7:327-338.

CONNELL, J.H. 1975. Some mechanisms producing structure in natural communities, in Ecology and evolution of communities, CODY M.L. and J.M. DIAMOND Eds., Harvard Univ. Press, Cambridge, Mass.: 460-490.

CULVER, D.C. 1970. Analysis of simple cave communities: niche separation and species packing. Ecology 51:949-958.

CULVER, D.C. 1971. Analysis of simple cave communities. III. Control of abundance. Am. Midl. Nat. 85:173-187.

CULVER, D.C. 1973. Competition in spatially heterogeneous systems: an analysis of simple cave communities. Ecology 54:102-110.

CULVER, D.C. 1976. The evolution of aquatic cave communities. Am. Nat. 110:945-957.

DAVIDSON, D.W. 1980. Some consequences of diffuse competition in a desert ant community. Am. Nat. 116:92-105.

DICKSON, G.W. 1976. Variation in the ecology, morphology and behavior of the troglobitic amphipod crustacean Crangonyx antennatus Packard (Crangonychidae) from different habitats. Master's Thesis, Old Dominion University, Norfolk, Va.

GANTMACHER, F.R. 1959. Applications of the theory of matrices. Wiley Interscience, New York, N.Y.

GLEDHILL, T. 1977. Numerical fluctuations of four species of subterranean amphipods during a five year period. Crustaceana Suppl. 4:144-152.

HOLSINGER, J.R., R. BAROODY, and D. CULVER 1976. The invertebrate cave fauna of West Virginia. West Virginia Speleological Survey Bulletin 7, 82 p.

LEVINE, S.H. 1976. Competitive interactions in ecosystems. Am. Nat. 110:903-910.

LEVINS, R. 1975. Evolution in communities near equilibrium, in: Ecology and evolution of communities, CODY M.L. and J.M. DIAMOND eds., Harvard Univ. Press, Cambridge, Mass. 
MAY, R.M. 1973. Stability and complexity in model ecosystems. Princeton Univ. Press, Princeton, N.J.

MAY, R.M. 1974a. Ecosystem patterns in randomly fluctuating environments, in: Progress in theoretical biology, volume 3, ROSEN R. and F.M. SNELL eds., Academic Press, New York, N.Y.

MAY, R.M. 1974b. How many species: some mathematical aspects of the dynamics of populations, in: Lectures on mathematics in the life sciences 6: some mathematical questions in biology V, COWAN J.D. ed., Amer. Math. Soc., Providence, R.I. .

MAY, R.M. and W.J. LEONARD. 1975. Nonlinear aspects of competition between three species. SIAM J. Appl. Math. 29:243-253.

NEILL, W.E. 1974. The community matrix and the interdependence of the competition coefficients. Am. Nat. 108:399-408.

POULSON, T.L., and W.B. WHITE. 1969. The cave environment. Science 165:971-981.

ROUGHGARDEN, J. 1975. Population dynamics in a stochastic environment: spectral theory for the linearized $\mathrm{N}$-species Lotka-Volterra competition equations. Theoret. Popul. Biol. 7:1-12.

SEARLE, S.R. 1966. Matrix algebra for the biological sciences. J. Wiley and Sons, New York, N.Y.

SEIFERT, R.P., and F.H. SEIFERT. 1976. A community matrix analysis of Heliconia insect communities. Am. Nat. 110:461-483.

SMALE, S. 1976. On the differential equations of species in competition. J. Math. Biol. 3:5-7.

STROBECK, C. 1973. N species competition. Ecology 54:650-654.

\section{APPENDIX 1}

1. Gallohan Cave No. 1 (unpublished data of James Estes)

Number of individuals per $\mathrm{ft}^{2}\left(0.09 \mathrm{~m}^{2}\right)$

$\begin{array}{lccc}\text { Date } & \text { L. usdagalun } & \text { C. recurvata } & \text { C. antennatus } \\ \mathrm{XI} / 74 & 8.78 & 3.61 & 0.44 \\ \mathrm{II} / 75 & 6.33 & 2.00 & 0.50 \\ \mathrm{VI} / 75 & 5.94 & 0.72 & 0.61 \\ \text { VIII/75 } & 5.67 & 4.50 & 0.67 \\ \mathrm{XI} / 75 & 8.61 & 1.94 & 0.50\end{array}$

2. Court Street Cave

Number of individuals per $\mathrm{ft}^{2}\left(0.09 \mathrm{~m}^{2}\right)$

$\begin{array}{lccc}\text { Date } & P . \text { holsingeri } & \text { S. emarginatus } & \text { S. spinatus } \\ \text { VI/67 } & 0.11 & 0.67 & 2.56 \\ \text { VIII/67 } & 0.11 & 0.44 & 1.78 \\ \text { XI/67 } & 0.43 & 0.43 & 1.00 \\ \text { II/68 } & 0.56 & 0.89 & 1.33 \\ \text { VI/68 } & 0.89 & 0.22 & 1.44 \\ \text { V/68 } & 0.14 & 0.71 & 1.57 \\ \text { IV/69 } & 0.11 & 0.56 & 1.56\end{array}$


3. Gallohan Cave No. 2 (Dickson, 1976)

Number of individuals $/ \mathrm{m}^{2}$

Date

VIII $/ 74$

$\mathrm{XI} / 74$

II $/ 75$

VI/75
C. antennatus

17

5

4

C. recurvata

L. usdagalun

4. Spangler Cave (Dickson, 1976)

Number of individuals $/ \mathrm{m}^{2}$

$\begin{array}{lcc}\text { Date } & \text { C. antennatus } & \text { C. recurvat } \\ \text { VIII } / 74 & 125 & 23 \\ \mathrm{XI} / 74 & 23 & 25 \\ \mathrm{II} / 75 & 18 & 20 \\ \mathrm{VI} / 75 & 15 & 40\end{array}$

\section{APPENDIX 2}

The signs of the terms $\mathrm{a}_{\mathrm{ij}}$ in equation [9] depend on:

$$
\left|\begin{array}{lll}
\left(1-\alpha_{23} \alpha_{32}\right) & \left(-\alpha_{12}+\alpha_{32} \alpha_{13}\right) & \left(-\alpha_{13}+\alpha_{12} \alpha_{23}\right) \\
\left(-\alpha_{21}+\alpha_{23} \alpha_{31}\right) & \left(1-\alpha_{13} \alpha_{31}\right) & \left(-\alpha_{23}+\alpha_{13} \alpha_{21}\right) \\
\left(-\alpha_{31}+\alpha_{21} \alpha_{32}\right) & \left(-\alpha_{32}+\alpha_{12} \alpha_{31}\right) & \left(1-\alpha_{12} \alpha_{21}\right)
\end{array}\right|
$$

The order of species is (1) Pseudobaicalasellus holsingeri, (2) Stýgobromus emarginatus, and (3) $S$. spinatus. Since all sub-communities of two species occur in isolation (Holsinger et al., 1976), all these sub-communities must be stable, and all diagonal elements of (Al) are positive.

$$
\left|\begin{array}{lll}
+ & ? & ? \\
? & + & ? \\
? & ? & +
\end{array}\right|
$$

Competition between $S$. emarginatus and $S$. spinatus is much less than for any other pair, so $\alpha_{23}$ and $\alpha_{32}$ are much less than the other $\alpha$ 's. Then the expected signs of the elements of (A1) are:

$$
\left|\begin{array}{ccc}
+ & - & - \\
- & + & + \\
- & + & +
\end{array}\right|
$$

which is the result given in [12]. 